\title{
Predicción de dos ciclones mediterráneos intensos consecutivos en marzo de 2018
}

https://doi.org/10.31978/639-19-010-0.517

\author{
Joan Campins Pons ${ }^{1}$ (jcampinsp@aemet.es) \\ María Ángeles Picornell Alou' ${ }^{1}$ (mpicornella@aemet.es)
}

${ }^{1}$ AEMET / Delegación Territorial en Illes Balears

\begin{abstract}
RESUMEN
A finales de marzo de 2018 y de forma consecutiva dos intensos ciclones mediterráneos afectaron a las islas Baleares y provocaron fenómenos meteorológicos de alto impacto. El primer ciclón (días 19 y 20) afectó principalmente a la isla de Menorca, con precipitaciones abundantes y sobre todo con viento fuerte y temporal marítimo (en la boya de Mahón se registraron vientos sostenidos de $35 \mathrm{kt}$ y una altura significativa del oleaje de $6 \mathrm{~m}$ ). El segundo ciclón (días 24 y 25) afectó principalmente a Mallorca, donde las precipitaciones fueron muy intensas (hasta $242 \mathrm{~mm}$ en $24 \mathrm{~h}$ y $311 \mathrm{~mm}$ acumulados en esos dos días) y también se registró viento fuerte. Si bien ambos ciclones se formaron en el mar Balear y se intensificaron rápidamente, su desplazamiento hacia el este fue muy diferente. Así el primero se desplazó con una velocidad uniforme, mientras que el segundo se mantuvo estacionario las primeras horas pero se desplazó muy rápidamente en las siguientes horas.

En este trabajo se estudia la habilidad del modelo determinista del ECMWF para predecir la trayectoria e intensidad de los dos ciclones citados. También se estima la relación de la predicción de la posición y la intensidad de los dos ciclones con la precipitación y el viento previstos en cada caso.
\end{abstract}

PALABRAS CLAVE: ciclones mediterráneos; tiempo de alto impacto; predicción a corto y medio plazo; predecibilidad; modelo determinista del ECMWF.

\section{INTRODUCCIÓN}

En el Mediterráneo occidental, el mes de marzo se considera climatológicamente como el inicio de la primavera y, por tanto, como un periodo de transición entre la estación fría y la cálida. En la misma se alternan periodos de tiempo típicamente invernales con otros de tiempo más estable. Por este motivo en esta región es habitual la formación o la entrada de ciclones relacionados con vaguadas asociadas al chorro polar que, si se ondulan mucho, pueden dar lugar a la formación de danas. Estas borrascas frías vienen acompañadas de precipitaciones y viento, y ocasionalmente producen tiempo adverso.

En las islas Baleares marzo de 2018 se caracterizó por una primera mitad con temperaturas más altas de lo normal seguida de una segunda quincena más fría de lo normal. Fue en este segundo periodo en el que se registraron intensas precipitaciones en Mallorca y Menorca, con acumulaciones muy superiores a lo normal. Así por ejemplo en Menorca se registró el triple del promedio mensual normal y en Mallorca el doble (AEMET, 2018). Además, marzo de 2018 se puede calificar en las islas Baleares como un mes muy ventoso. Estos episodios de tiempo adverso están directamente relacionados con el paso dos ciclones intensos en una misma semana, en concreto la que va del 19 al 25 de marzo de 2018. 
A pesar de que los modelos deterministas han mejorado mucho en los últimos años, en los episodios con baja predecibilidad su error de predicción puede ser elevado. En nuestras latitudes muchos de estos episodios están relacionados con ciclones, por lo que una forma alternativa a los métodos convencionales de estimar los errores de los modelos numéricos puede llevarse a cabo estimando los errores de dichos modelos al identificar y seguir (tracking) los ciclones previstos respecto a los analizados y de este modo estudiar cómo estos errores aumentan con el alcance de la predicción (FroudE et al., 2007).

En este trabajo se estudia la habilidad del modelo numérico determinista de escala global del Centro Europeo de Predicción a Medio Plazo (European Centre for Medium-range Weather Forecast; ECMWF), denominado HRES por high resolution, para predecir a corto y medio plazo la trayectoria y la intensidad de dos ciclones mediterráneos que afectaron a las islas Baleares a finales de marzo de 2018. La detección y seguimiento de los ciclones se realiza a partir de la salida del citado modelo numérico y con la metodología desarrollada en PicoRnell et al., 2001 y CAMPIns et al., 2006. Además de los campos previstos del modelo HRES, utilizaremos como referencia los campos analizados del mismo modelo para la verificación de dichas predicciones.

El presente trabajo está estructurado de la forma siguiente. La sección 2 describe el tiempo adverso asociado a los dos ciclones mencionados. La sección 3 analiza las predicciones deterministas a corto y medio plazo de ambos ciclones y se comparan con los análisis derivados del mismo modelo numérico de predicción. Finalmente, las principales conclusiones del trabajo así como algunos comentarios finales se presentan en la sección 4.

\section{TIEMPO ADVERSO Y CICLONES}

A continuación se describe la evolución de los dos ciclones a partir de los análisis del modelo HRES del ECMWF cada 6 horas, así como los principales fenómenos adversos observados asociados a cada uno de ellos.

\subsection{Ciclón del 19 y 20 de marzo de 2018}

El primer ciclón se formó el día 19 a las 12 UTC como una pequeña y débil depresión situada al norte de los Pirineos. Se trata probablemente de una depresión secundaria de una borrasca mayor situada al oeste de Francia. Esta débil depresión se desplazó a una velocidad uniforme $(\sim 20 \mathrm{~km} / \mathrm{h})$ hacia el sureste a la vez que se intensificaba (figura 2a). La profundización fue muy rápida, con una caída de la presión a nivel del mar (MSLP) de 9,6 hPa en 24 h (figura 2b) y el consiguiente aumento del gradiente de presión. El momento de máxima intensidad se dio el día 20 a las 12 UTC, con el ciclón situado al este de Menorca, una presión mínima de 992,7 hPa y un gradiente medio de presión de 4,5 hPa/100 km. Aunque el ciclón prosiguió desplazándose hacia el mar Tirreno, en este estudio solo se analizará hasta el 20 a las 18 Z, puesto que a partir de este momento se puede considerar que ya no afectó a las islas Baleares.

El ciclón afectó principalmente a Menorca, con precipitaciones intensas, viento fuerte del noroeste y fuerte temporal marítimo, y en menor medida el norte de Mallorca. Así por ejemplo, el día 20 se registraron rachas de hasta $87 \mathrm{~km} / \mathrm{h}$ en el aeropuerto de Menorca y la boya situada al sureste de Menorca registró vientos de $35 \mathrm{kt}$ (fuerza 8 en la escala de Beaufort) y mar muy gruesa (altura significativa de 6,0 m y una altura máxima de 10,5 m). Las precipitaciones fueron abundantes en toda Menorca, con un máximo de $69 \mathrm{~mm}$ en 24 h en la estación de Cala Galdana. En Mallorca se registraron rachas de $93 \mathrm{~km} / \mathrm{h}$ en el Puig d'Alfàbia y $82 \mathrm{~km} / \mathrm{h}$ en el faro de Capdepera. También se registraron precipitaciones en Mallorca, no tan abundantes como en Menorca, aunque en forma de nieve en la sierra de Tramuntana.

\subsection{Ciclón del 24 y 25 de marzo de 2018}

Unos pocos días después, el 24 a las 06 UTC, se formó entre Cataluña y las islas Baleares una nueva depresión débil. En este caso también se puede considerar la formación del centro de baja presión como una 
ciclogénesis secundaria, provocada en este caso por el ciclón Hugo que en estos momentos se encontraba situado en el mar Cantábrico. La depresión mediterránea inicialmente se movió muy lentamente hacia las islas Baleares, pero a partir del 25 a las 00 UTC se desplazó rápidamente hacia el norte de África (figura 6a). El momento de máxima intensidad se dio el 25 a las $06 \mathrm{Z}$ con un gradiente medio de presión de $3,9 \mathrm{hPa} / 100 \mathrm{~km}$ (figura 6b) y una presión mínima de 987,9 hPa.

Este ciclón afectó principalmente a Mallorca, que registró precipitaciones muy intensas y viento fuerte. Las precipitaciones más importantes se concentraron en la sierra de Tramontana, con acumulaciones en dos días de $311 \mathrm{~mm}$ en Son Torrella (152 y 159 mm), 212 mm en Lluc (116 y $96 \mathrm{~mm}$ ) y 125 mm en el Puig d'Alfàbia $(65$ y $60 \mathrm{~mm})$. En otras estaciones de Mallorca igualmente se recogieron acumulaciones importantes, aunque mucho menores que los valores mencionados. En Menorca, Ibiza y Formentera también se registraron precipitaciones, si bien en ningún caso se superaron los $20 \mathrm{~mm}$ en 24 horas. Las elevadas cantidades de precipitación registradas en Mallorca, concentradas en zonas elevadas, apuntan a una fuerte componente orográfica de las mismas, favorecidas por la persistencia del flujo del noroeste sobre la sierra de Tramontana. El viento fue fuerte en Mallorca en ambos días, con rachas de $123 \mathrm{~km} / \mathrm{h}$ el 24 y de $128 \mathrm{~km} / \mathrm{h}$ el 25 en el Puig d'Alfàbia y de $87 \mathrm{~km} / \mathrm{h}$ en Banyalbufar el día 24. En las zonas costeras se registraron vientos del noroeste de fuerza 7 y mar muy gruesa.

\section{PREDICCIÓN DE LOS CICLONES}

A la hora de investigar las predicciones a corto y medio plazo del modelo HRES delECMWF se compararán las evoluciones de dichos ciclones, en diferentes alcances de predicción, con los ciclones analizados por el mismo modelo. Nos centraremos en la predicción de la posición, presión a nivel del mar (MSLP) en el centro y el gradiente medio de presión del ciclón a lo largo de la trayectoria del mismo, con especial interés en el momento de mayor intensidad. En este trabajo utilizaremos el gradiente medio de presión como medida de la intensidad del ciclón.

\subsection{Predicción del ciclón del 19 y 20 de marzo de 2018}

En primer lugar se analiza el error en la posición y en la presión en el centro del primer ciclón para diferentes alcances de predicción en el momento de máxima intensidad (día 20 a las 12 UTC). En la figura 1a se aprecia cómo el error en la localización de la depresión prevista es pequeño para alcances cortos y muy grande (> $200 \mathrm{~km}$ ) para la predicción a 108 horas. De un modo general se puede decir que el error aumenta con el alcance y se mantiene en unos valores aceptables para alcances de hasta 4 días. El error absoluto en la predicción de la presión en el centro del ciclón se presenta en la figura 1b. Este grafico muestra que el error absoluto de la presión en el centro del ciclón aumenta con el alcance de predicción de un modo gradual, pero es sobre todo a partir del H+84 en que este error aumenta bruscamente. El error absoluto en la predicción del gradiente medio de presión respecto al alcance muestra un resultado parecido al de la presión en el centro del ciclón. Es decir, para alcances cortos el error absoluto se mantiene bajo, pero aumenta mucho para las predicciones mayores o iguales a tres días.

Tanto el error en la posición como la intensidad del ciclón previsto respecto al analizado aumentan con el alcance de predicción a un ritmo más o menos uniforme hasta un cierto alcance en el que aumentan bruscamente (pero no en el mismo alcance). Este cambio brusco supone una disminución acusada de la predecibilidad de este caso, que se puede situar en 4 días para la posición y en 3 días para la intensidad.

Por tanto vemos que existen marcadas diferencias en las predicciones del momento de máxima intensidad según el alcance de predicción. Pero ¿qué ocurre en la formación y posterior evolución del ciclón, son los errores mayores o menores? Para responder a estas preguntas a continuación se comparan la trayectoria y la evolución del valor mínimo de presión previstas y analizadas de una predicción a corto plazo (la del 18 a las 12 UTC) y otra a un plazo mayor (la del 16 a las 00 UTC). 
a)

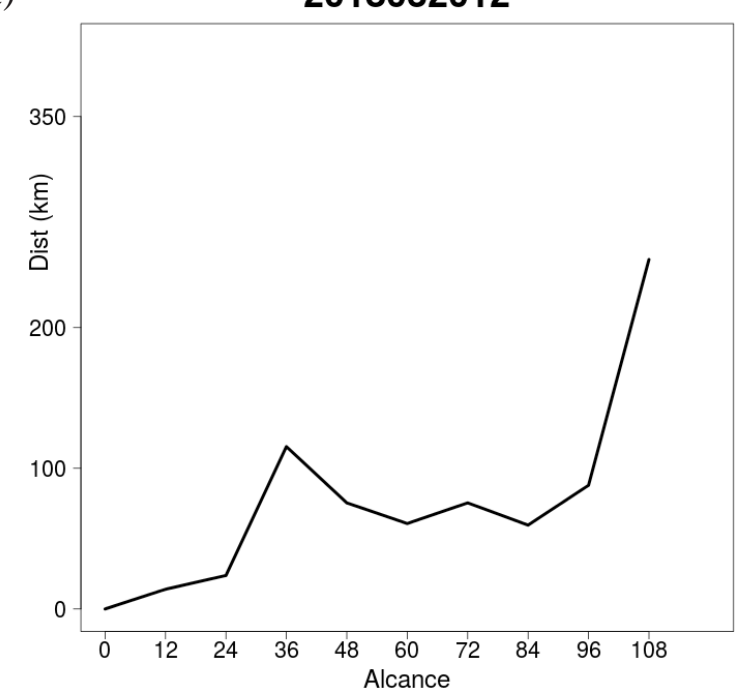

2018032012

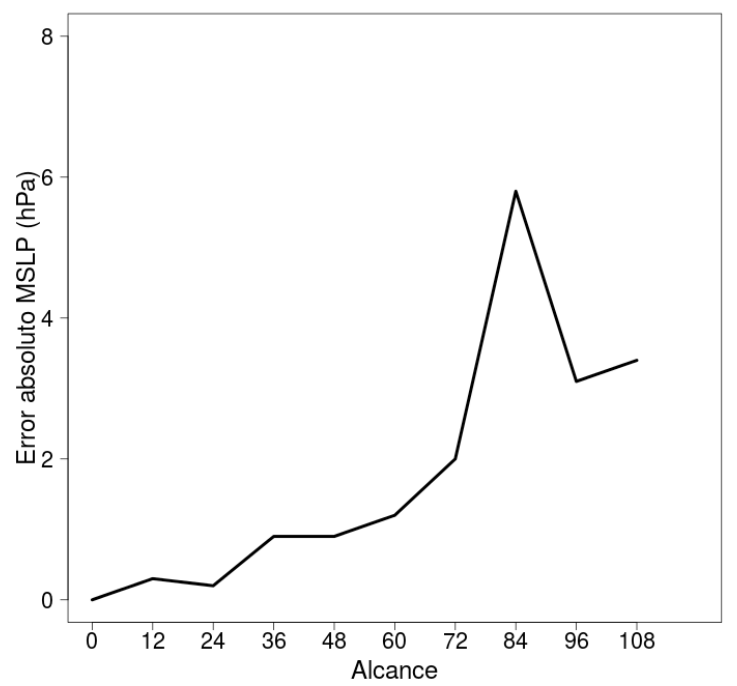

b)

Figura 1. a) Error en la posición (en km) y b) error absoluto de la MSLP en el centro (en hPa) de los ciclones previstos respecto al ciclón analizado en función del alcance de predicción.

Momento de verificación: 20 de marzo de 2018 a las 12 UTC.

La predicción del 18 a las 12 UTC se realizó 24 horas antes de la formación del ciclón y 48 horas antes de que este alcanzara su máxima intensidad. Se trata, por tanto, de una predicción de corto plazo para todo el ciclo de vida del ciclón. La figura 2a muestra que la posición del ciclón es muy parecida a la analizada no solo en el lugar de su formación sino también a lo largo de toda la trayectoria. La evolución de la presión en el centro (figura 2b) también es muy parecida a la analizada, con valores previstos un poco mayores a los analizados en las predicciones de menor alcance y un poco menores a partir del H+42. El gradiente de presión previsto también es muy parecido al analizado (no mostrado).

La predicción del día 16 a las 00 UTC se realizó 3,5 días (84 horas) antes de la formación del ciclón y 4,5 días (108 horas) antes de su máxima intensidad. Esta predicción desplaza hacia el sur la formación del ciclón y este error aumenta con el tiempo (figura 3a). La figura 3 b muestra que el error en la predicción del mínimo de presión es muy elevado en el momento de la formación del ciclón $(5,4 \mathrm{hPa})$ y, aunque se reduce un poco a medida que aumenta el alcance, sigue siendo elevado en el momento de máxima intensidad (3,4hPa).

a)

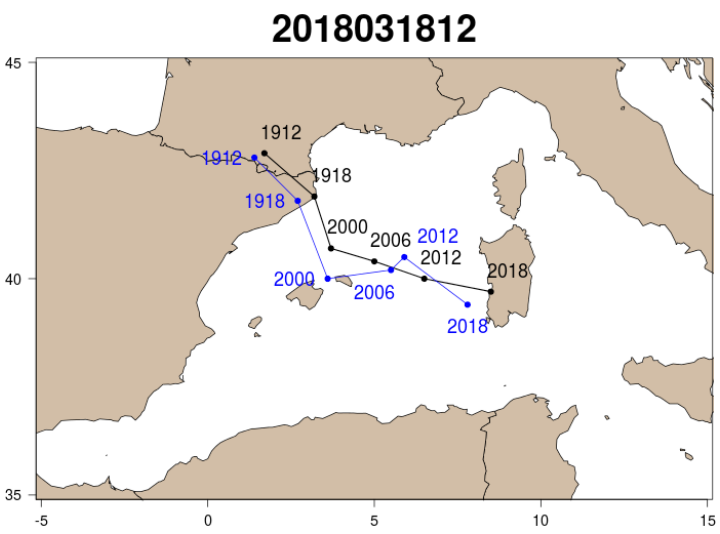

2018031812

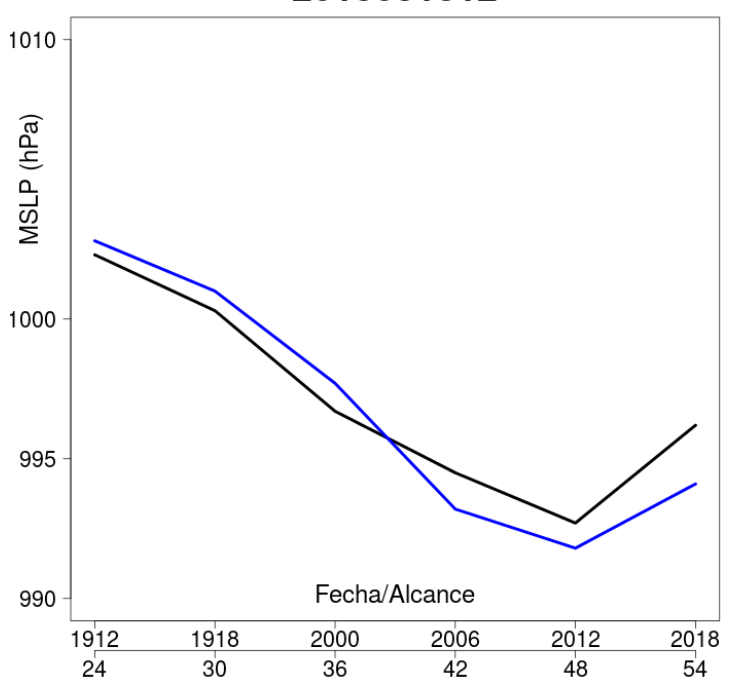

b)

Figura 2. a) Trayectorias y b) MSLP en el centro (en hPa) del ciclón previsto el 18 de marzo de 2018 a las 12 UTC (línea azul) respecto al ciclón analizado (línea negra). 
a)

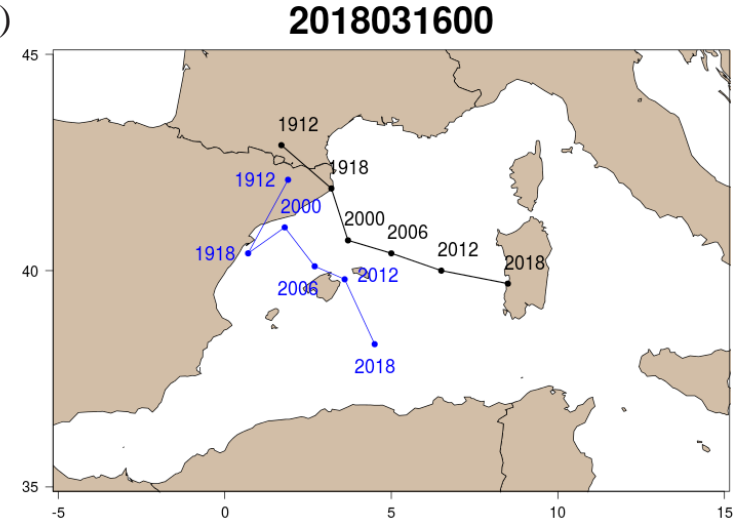

2018031600

b)

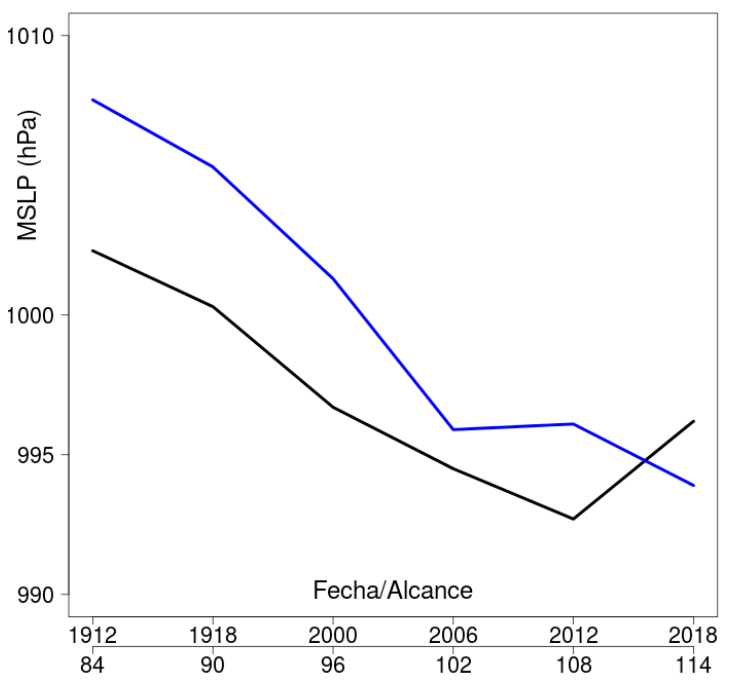

Figura 3. a) Trayectorias y b) MSLP en el centro (en hPa) del ciclón previsto el 16 de marzo de 2018 a las 00 UTC (línea azul) respecto al ciclón analizado (línea negra).

Los errores en la predicción de la posición y la intensidad del ciclón implican errores en la predicción del viento y de la precipitación. La comparación de los campos previstos de viento y precipitación respecto a los valores observados es compleja. En su lugar se realiza en primer lugar una verificación cualitativa del viento previsto a 10 metros para diferentes alcances respecto al analizado en el momento de máxima intensidad del ciclón. La figura 4a muestra cómo la predicción del 16 a las 00 UTC para el momento de máxima intensidad (20 a las 12 UTC) da un viento del noreste sobre las islas Baleares en vez del noroeste. Además, la zona de viento más intenso prevista es mucho menos extensa que la analizada. En cambio la predicción del 18 a las 12 UTC para el 20 a las 12 UTC (figura 4b) sí da viento del noroeste sobre las islas Baleares con una fuerza prevista similar a la analizada (aunque ligeramente menor). Las distribuciones de precipitación acumulada en 24 horas también son diferentes en las dos predicciones mencionadas. Una comparación subjetiva respecto a las imágenes radar y a las observaciones de precipitación muestra una buena concordancia con la predicción a corto plazo pero no con la de medio plazo.

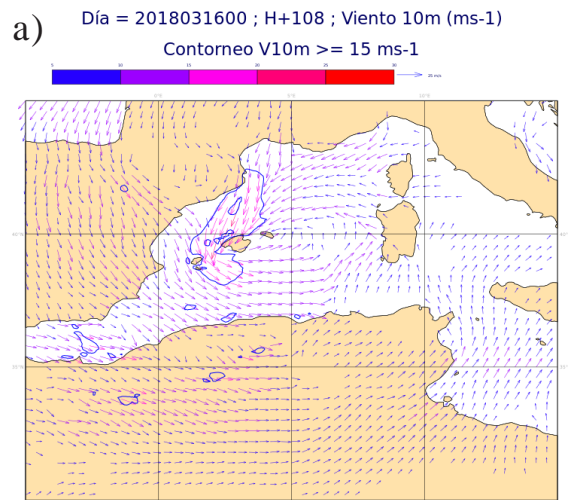

b)

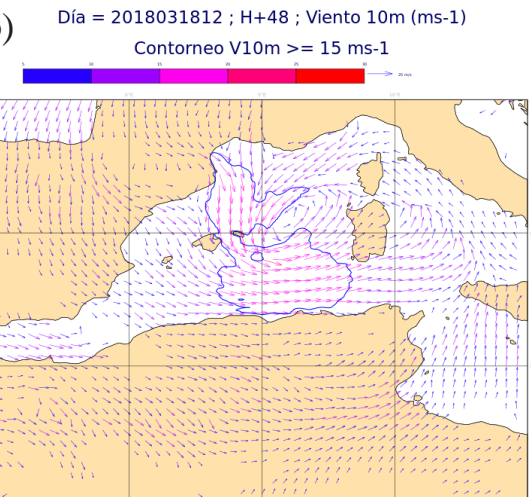

c) Día $=2018032012 ; \mathrm{H}+0$; Viento $10 \mathrm{~m}(\mathrm{~ms}-1)$ Contorneo $\mathrm{V} 10 \mathrm{~m}>=15 \mathrm{~ms}-1$

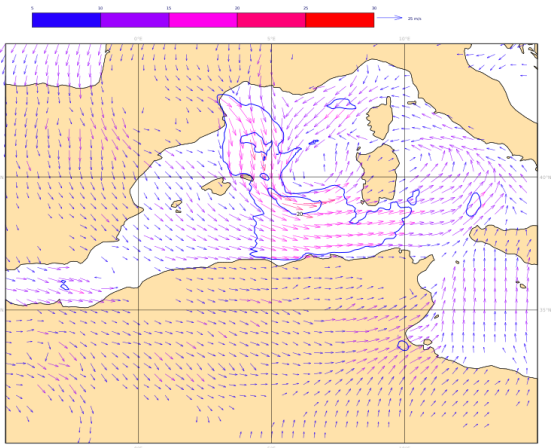

Figura 4. Predicción del viento a 10 metros del día 16 a las 00 UTC a 108 horas (a) y del día 18 a las

12 UTC a 48 horas (b) respecto al viento a 10 metros analizado el día 20 las 12 UTC (c).

El tamaño y el color de las fechas dependen del módulo del viento (cada $5 \mathrm{~m} / \mathrm{s}$ )

y además se contornean en azul los valores mayores de $15 \mathrm{~m} / \mathrm{s}$ en intervalos de $5 \mathrm{~m} / \mathrm{s}$. 


\subsection{Predicción del ciclón del 24 y 25 de marzo de 2018}

La figura 5 muestra el error de predicción de la posición y el error absoluto de la presión en el centro del ciclón respecto al alcance para el día 25 a las 00 UTC. Si bien la máxima intensidad del ciclón se dio 6 horas más tarde, en el subapartado 2.2 se ha apuntado que a partir de las 00 UTC del día 25 el segundo ciclón cambió bruscamente su desplazamiento y como veremos más adelante ello tuvo mucha importancia en los errores de las diferentes predicciones por lo que las predicciones para diferentes alcances se referirán a este momento. En la figura 5a se aprecia que el error en la posición aumenta muy rápidamente con el alcance y solamente para las predicciones hasta 36 horas el error es menor a $100 \mathrm{~km}$. El aumento del error con el alcance no es constante y es muy elevado para los alcances de 4 o 5 días, aunque a 2 días el error también es muy elevado (> $200 \mathrm{~km}$ ). El error absoluto en la predicción del mínimo de presión (figura 5b) en general también aumenta con el alcance, pero lo hace de un modo más irregular, con errores realmente bajos $(<1 \mathrm{hPa})$ en las predicciones a 12, 36, 48, 60 y 84 horas y errores muy elevados sobre todo para la predicción a 5 días. El error absoluto del gradiente de presión sigue la misma pauta que el mínimo de presión (no mostrado). En este caso y a diferencia del primer ciclón, la intensidad tiene mayor predecibilidad que la posición.

a)

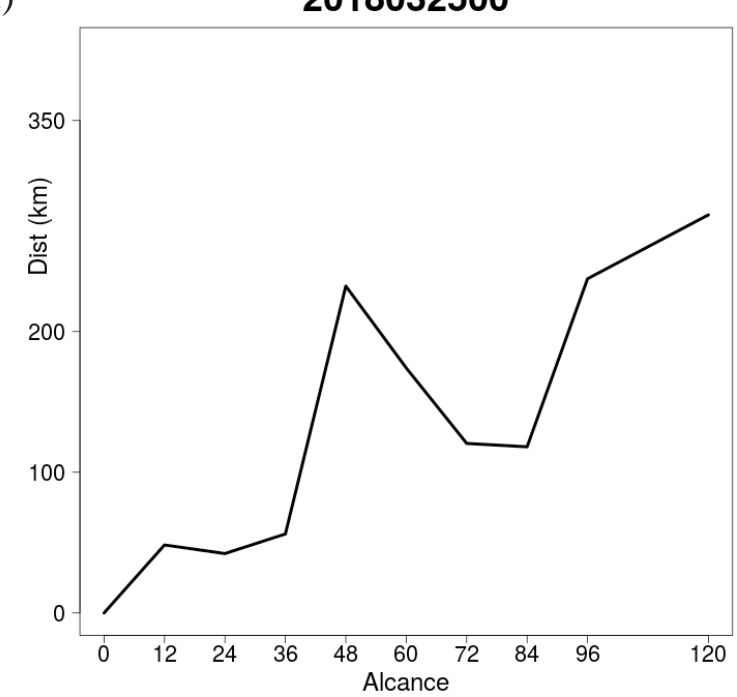

2018032500

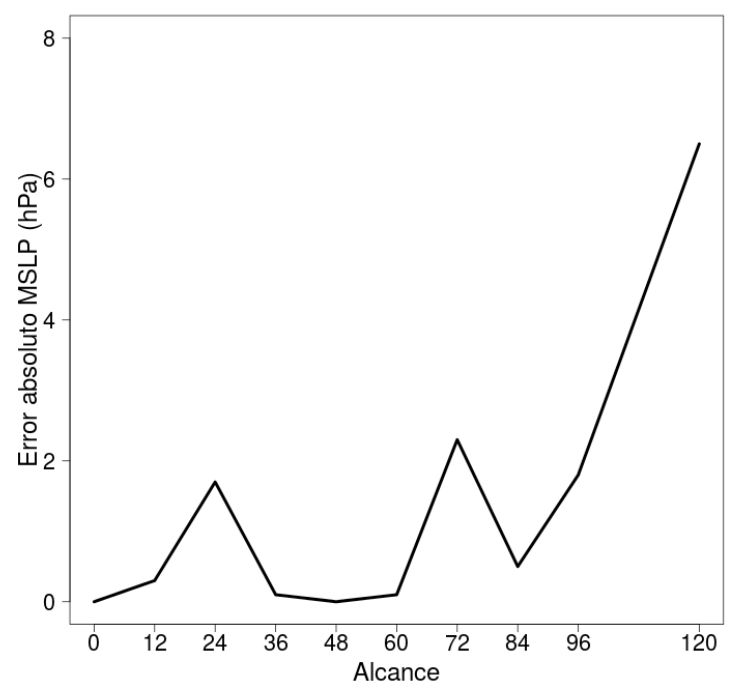

b)

Figura 5. a) Error en la posición (en km) y b) error absoluto de la presión en el centro (en hPa) de los ciclones previstos respecto al ciclón analizado en función del alcance de predicción. Momento de verificación: 25 de marzo de 2018 a las 00 UTC.

La figura 5 muestra que la predicción a 48 horas de la posición del ciclón para el día 25 a las 00 UTC presenta un error muy elevado para la posición y muy pequeño en la presión en el centro y en su gradiente. Se trata de la predicción realizada el día 23 a las 00 UTC y para la misma a continuación se compara la trayectoria del ciclón prevista respecto a la analizada, así como su gradiente medio a lo largo del tiempo (figura 6). En el momento inicial (el 24 a las 06 UTC; H+30) el ciclón previsto se sitúa en una posición prácticamente idéntica al analizado y la intensidad prevista es muy parecida a la analizada, aunque un poco menor. En las 12 horas siguientes (hasta el 24 a las 18; H+42) el ciclón previsto se mueve lentamente hacia el sureste, separándose un poco $(<100 \mathrm{~km})$ de la analizada; el error en la intensidad sigue siendo pequeño. Pero el día 25 a las 00 UTC $(\mathrm{H}+48)$ el ciclón previsto se desplaza muy rápidamente hacia el norte de África, mientras que el ciclón analizado permanece muy próximo a las islas Baleares (ambos ciclones están separados más de $200 \mathrm{~km}$ ). Sin embargo, en este momento la intensidad prevista sigue con un error relativamente pequeño. En el momento de máxima intensidad del ciclón (el 25 a las 06 UTC; H+54) es al revés, el error en la posición prevista es pequeño $(<100 \mathrm{~km})$ pero el de intensidad es muy grande $(1,75 \mathrm{hPa} / 100 \mathrm{~km})$. Finalmente, el 25 
a las 12 UTC (H+60) el error tanto de la posición como de la intensidad del ciclón previsto son elevados ( $>200 \mathrm{~km} \mathrm{y}>1 \mathrm{hPa} / 100 \mathrm{~km}$ respectivamente). En resumen, la predicción del día 23 a las $00 \mathrm{UTC}$ en el primer tramo presentó pequeños errores en la posición e intensidad del ciclón. Este primer periodo de la evolución del ciclón, de un menor alcance de predicción, coincide con un lento desplazamiento a través de las islas Baleares. En cambio, el 25 las 00 UC si bien el ciclón analizado sigue próximo a las islas Baleares, la predicción lo desplaza demasiado pronto hacia el sureste. A partir de este momento el error en la posición o en la intensidad ya fueron elevados.

La trayectoria prevista del ciclón del día 21 a las 00 UTC (no mostrada) difiere mucho respecto de la analizada, sobre todo para el 25 a las 00 y a las 06 UTC. El gradiente medio de presión previsto (no mostrado) es muy similar al previsto el 23 a las 00 UTC, es decir, con un error pequeño hasta el día 25 a las 00 UTC y muy grande, con una fuerte subestimación a partir de ese momento (no mostrado).

a)

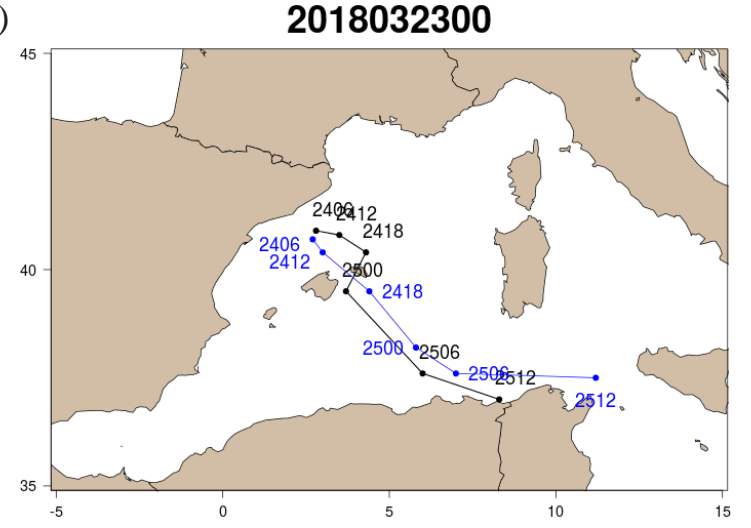

2018032300

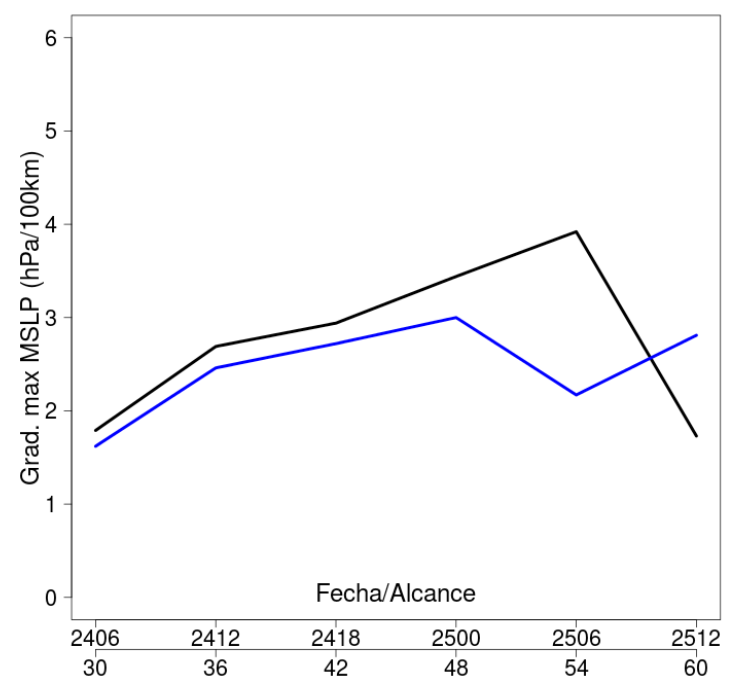

b)

Figura 6. a) Trayectorias y b) gradiente medio de MSLP (en hPa/100 km) del ciclón previsto en la pasada del día 23 de marzo de 2018 a las 00 UTC (línea azul) respecto al ciclón analizado (línea negra).

Para profundizar en las diferencias entre las predicciones de los ciclones a corto y a medio plazo, se pueden investigar las diferencias en los campos de viento y de precipitación acumulada. Si tomamos el 25 a las 00 UTC como momento de verificación, la predicción a dos días (esto es, la del día 23 a las 00 UTC) del viento a 10 metros es bastante parecida a la analizada, aunque el viento fuerte previsto se desplaza demasiado hacia el sur, en congruencia con el campo de presión al nivel del mar. En cambio la predicción a 4 días (esto es, la del día 21 a las 00 UTC) desplaza mucho más el viento fuerte hacia el sur, sin que este afecte en este caso a las islas Baleares. Por lo que respecta a la precipitación acumulada hay que distinguir entre las predicciones para el día 24 y el 25. En el primer día (de las 00 UTC del 24 a las 00 UTC del 25), los ciclones previstos se mueven lentamente alrededor de las islas, sobre todo en la pasada del día 23 a las 00 UTC, por lo que la precipitación acumulada afecta de lleno a esa región. En la figura 7 se pueden ver las predicciones que se hicieron los días 21,23 y 24 a las 00 UTC de la precipitación acumulada en 24 horas válidas para el día 24 (de las 00 UTC del 24 a las 00 del 25). Para ese día, las tres predicciones son bastante parecidas entre sí y cualitativamente parecidas a las observaciones de precipitación y las imágenes radar (no mostrado), aunque cuantitativamente los valores previstos están muy lejos de los observados. Las predicciones a corto plazo muestran una intensificación de la precipitación acumulada en la sierra de Tramuntana, por tanto relacionada con la orografía, pero como la orografía del modelo utilizado dista mucho de la real los valores previstos también están subestimados. 
a) Día $=2018032100$ Pcp. Acum. $(24$ h): H+72 a H+96

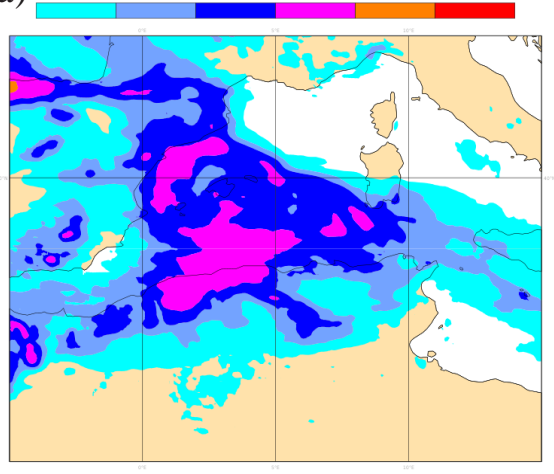

b) Día $=2018032300$ Pcp. Acum. $(24 \mathrm{~h}): \mathrm{H}+24$ a H+48

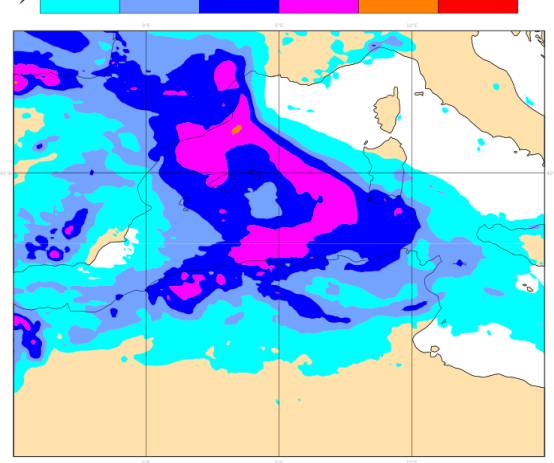

c) Día $=2018032400$ Pcp. Acum. $(24$ h): $\mathrm{H}+0$ a H+24

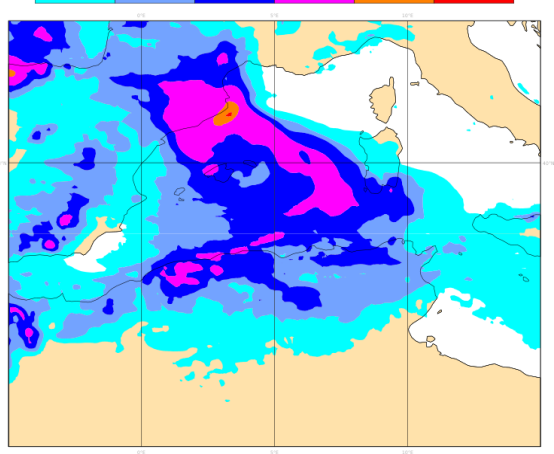

Figura 7. Predicciones del día 21 a las 00 UTC (a), del 23 a las 00 UTC (b) y del 24 a las 00 UTC (c) de la precipitación acumulada en 24 horas para el día 24 (de las 00 UTC del 24 a las 00 UTC del 25).

En cambio las predicciones de las precipitaciones acumuladas en 24 horas del 25 (de las 00 UTC del 25 a las 00 del 26) se concentran muy al sur, sobre el norte de África, tanto para la pasada del 23 a las 00 UTC pero sobre todo la del 21 a las 00 UTC (no mostradas). Como ya se comentó anteriormente, estos errores en la precipitación acumulada son debidos principalmente a un desplazamiento prematuro hacia el sureste de la posición de los ciclones previstos.

\section{CONCLUSIONES Y DISCUSIÓN}

En este trabajo se ha estudiado la habilidad del modelo determinista del ECMWF para predecir a corto y medio plazo dos ciclones intensos que afectaron a las islas Baleares a finales de marzo de 2018. Para ello se ha utilizado una metodología objetiva que permite detectar y caracterizar ciclones a partir de modelos numéricos de predicción del tiempo. La comparación de los ciclones previstos respecto de los analizados en diferentes alcances permite conocer mejor la predecibilidad de los mismos. Este trabajo se centra en comparar la posición y la intensidad de los ciclones previstos respecto a los analizados. Ambos parámetros están directamente relacionados con los fenómenos adversos asociados, como por ejemplo el viento fuerte o las precipitaciones intensas.

Las principales conclusiones del trabajo son:

- Para el primer ciclón se comprueba que la predicción de la posición en el momento de máxima intensidad es buena hasta cuatro días antes (desde $\mathrm{H}+12$ a H+96), mientras que la predicción de la intensidad funciona bien para alcances un poco menores (desde $\mathrm{H}+12$ hasta $\mathrm{H}+72$ ).

- La predicción de la posición del segundo ciclón en el momento central de su evolución tiene un elevado error para alcances de $\mathrm{H}+48$ en adelante. Ello es debido a que estas predicciones no aciertan en el momento de la transición de un ciclón casi estacionario situado próximo a las islas Baleares y su posterior rápido desplazamiento hacia el norte de África. En cambio, la predicción de la intensidad del ciclón funciona bien hasta alcances de predicción mayores (hasta 96 horas).

- La predecibilidad de la posición y la intensidad de los dos ciclones estudiados es diferente. La trayectoria del primer ciclón es mucho más predecible que la del segundo. En cambio para la intensidad es al revés. Lógicamente al tratarse de solo dos casos no es posible extraer conclusiones generales, para ello es conveniente realizar un estudio similar con una muestra mucho mayor.

- Estos errores en la posición implican importantes errores en los campos previstos de precipitación y de viento, incluso con una buena predicción de la intensidad del ciclón. 
Este estudio pone de relieve algunos errores en la predicción de los ciclones pero no se analizan sus causas. Por ejemplo, en el segundo ciclón las predicciones a varios días no son capaces, o lo hacen con retraso, de prever el cambio brusco en el desplazamiento de la borrasca. Estos errores conllevan fallos en las predicciones de los fenómenos adversos, por lo que su diagnóstico es muy importante para conocer las limitaciones de los modelos que se usan y pueden ayudar en su mejora.

La metodología aplicada para diagnosticar errores en la predicción de los ciclones mediterráneos intensos se ha aplicado sobre el modelo determinista del ECMWF. Dicha metodología se puede extender también a las predicciones del modelo por conjuntos del ECMWF, como ya se hizo por ejemplo en PICORNELL y CAMPINS, 2018 para un caso de ciclón casi-tropical mediterráneo o medicane. Del mismo modo se puede aplicar esta metodología para el estudio de los errores de predicción de los ciclones pequeños e intensos a partir de modelos de alta resolución como el modelo determinista HARMONIE-AROME o la predicción por conjuntos del AEMET- $\gamma$ SREPS.

\section{REFERENCIAS}

Agencia Estatal de Meteorología (AEMET), 2018. Avance climatológico mensual de marzo de 2018. Delegación Territorial de AEMET en Illes Balears. http://www.aemet.es/documentos/es/serviciosclimaticos/ vigilancia_clima/resumenes_climat/ccaa/illes-balears/avance_climat_bal_mar_2018.pdf.

CAmpins, J., JansÀ, A. y Genovés, A., 2006. Three dimensional structure of Western Mediterranean cyclones. Int. J. Climatol., 26, 323-343. doi: 10.1002/joc.1275.

Froude, L. S., Bengtsson, L. y Hodges, K. I., 2007. The predictability of extratropical storm tracks and the sensitivity of their prediction to the observing system. Mon. Wea. Rev., 135, 315-333. doi: 10.1175/ MWR3274.1.

Picornell, M. A., Jansà, A., Genovés, A. y CAmpins, J., 2001. Automated database of mesocyclones from the HIRLAM (INM-0.5 ${ }^{\circ}$ ) analyses in the Western Mediterranean. Int. J. Climatol., 21, 335-354. doi: 10.1002/joc.621.

Picornell, M. A. y Campins, J., 2018. Predicción de medicanes. En: Santos, C. (Ed.). La física del caos en la predicción meteorológica, pp. 549-559. AEMET. 
